\title{
A Brief Analysis of Low-Carbon Agriculture Development Pattern
}

\author{
Meijuan Kang ${ }^{1}$ \\ ${ }^{1}$ School of Economics and Management, Changchun University of Science and Technology, Changchun 130022, \\ China \\ Correspondence: Meijuan Kang, School of Economics and Management, Changchun University of Science and \\ Technology, Changchun 130022, China. E-mail: kangmeijuan@163.com
}

Received: April 16, 2013

Accepted: May 5, 2013

Online Published: June 26, 2013

doi:10.5430/bmr.v2n2p96

URL: http://dx.doi.org/10.5430/bmr.v2n2p96

\begin{abstract}
Low-carbon agriculture demonstrated mild economy in the development of agriculture in which it different from ecotype agriculture, environmental agriculture and circulatory agriculture. Low-carbon agriculture is energy saving technology, solid carbon technology and it is also the reproducible agriculture recommended in the agriculture field in order to maintain the global environment safety and improves global climate. Low energy, low releasing, low pollute are the characteristics for the Low-carbon agriculture .It is new type agriculture with multi-functions such as: agriculture industry, safe security, climate adjustment, environment restraint and countryside finance. Development of low-carbon agriculture is an urgent need and great potential and promising. Low energy, low releasing, low pollute and high capability ,high efficiency, high profitability(three low or high) is the base for the Low-carbon agriculture develop mode .To finally increasing the farmer income and To improve agriculture efficiency and advance economy we have to defined the direction with Low-carbon , use energy saving and solid carbon development as tool .
\end{abstract}

Keywords: Low-carbon agriculture, Jilin Province, Current situation, Development pattern

Low-carbon agriculture is an ecological value-added agricultural operation and production mode which emphasis on the low consumption of resources and low-input, low emission of pollutants and efficient benefits, it is also an exploration of modern agriculture deal with of the global greenhouse effect, is an important component of the low-carbon economy section.

\section{Current status of Jilin Low-carbon agriculture development}

\subsection{Biomass energy industry is in the ascendant}

1) Using straw for power generation, the effect is significant

Crop straw is an important biomass energy resource, it has large resources, renewable, low sulfur and zero emissions of carbon dioxide and other advantages, the average sulfur content of only $3.8 \%$, much lower than the coal-fired $1 \%$ average sulfur content. It has important strategic significance to alleviate the country's energy shortage and the protection of national energy security and cleanness. Liaoyuan, Meihekou straw power generation projects have been started into production

2) Dacheng Group, Jilin Province, after several years of R \& D and manufacturing, the independent development of new technologies for the production of chemical alcohol with corn stalks and non-food plants. Using this technology, two tons of corn stover can produce one ton of polysaccharides, as long as the sugar can be used as raw materials for manufacturing chemical alcohol. All sugary biomass such as cassava and sugar cane, sugar beet squeezed residue can be used to manufacture chemical alcohol. Dacheng Group has acquired all patents with a variety of plant materials, production plant chemical alcohol technology to achieve the diversification of agricultural raw materials for processing.

3) Development prospects of biomass pellet fuel is broad

Jilin Province Fusong Quanyang Yongcai Wood Co., according to the decreasing the amount of timber accumulation, and underemployment problems due to the shortage of raw materials, timely adjust and optimize the industrial structure, developed biomass pellet fuel jointly with the Institute of Technology of Jilin the Huaguang ecological 
engineering, start construction soften the lignin under normal temperature and pressure, forest residue resources into the project to improve unit product calorific value technology. The project can produce an annual output of 12,500 tons of biomass pellet fuel. The fully implementation of the project can take full advantage of the local forestry resources, depth conversion of the resources, and promote the coordinated development of the environment and economic construction, with good economic, ecological and social benefits.

\subsection{Ecological agriculture chain overflowing with vigor}

Recently, Huinan County focusing on improving the comprehensive agricultural production capacity, the main line of development of ecological agriculture, vigorously promote the development of low-carbon agriculture, while focusing on the protection of the ecological environment in the development of the agricultural modernization. Huinan County's major breeding farms, in the past, the kind of dirt chaos exclusive turbulence dirty and messy scenario has already disappeared; In the fields, soil testing and fertilizer technology is widely used by local farmers, formed a "pig - Marsh - fruit (vegetable, fish) ecological agriculture chain", the majority of Huinan rural is a thriving, lively scene everywhere.

\section{Jilin Province low-carbon agricultural development mode selection}

Based on the current agricultural development status of the Jilin Province, Jilin Province should improve agriculture itself to address global climate change capacity, reduce agricultural greenhouse gas emissions, increase agricultural greenhouse gas carbon sinks, improve agricultural efficiency, agricultural product quality and yield problems etc., we should establish a set of complete low-carbon agricultural eco-compensation technology system, to provide a scientific basis for, Jilin Province agricultural policy-making and action decision making in the context of global climate change. Based on these principles, through comparative analysis of previous mode selection, I propose the following points for Jilin Province low carbon agricultural development mode, in order to provide the theoretical basis and practical reference for Jilin Province's development of low-carbon agriculture:

\subsection{Development mode of resource utilization}

This mode is the main object of study soil resources, land resources, fertilizer resources, forestry resources, water resources and agricultural environment, soil environment, water environment, ecological environment, taking field trials and pot experiments, chemical analysis as a core technology, mapping technology and engineering technology as a primary means of rural areas, agriculture and farmers as the main target.

Jilin Province is located in the corn belt, which has a unique straw resources, according to incomplete statistics, the province's annual straw yield is more than 4,000 tons, only corn stover yield reached more than 23 million tons. Nong'an county, Jilin Province, the use of straw is very common, the average straw every acre of corn estate will be able to suppress more than half a ton of straw carbon, so that not only take full advantage of the local straw resources, but also saves a lot of energy consumption. Jilin Province should make full use of the biological resources mainly crop straw, to reduce agricultural greenhouse gas emissions. Specifically in the use of straw resources can take the following approach:

1) Return straw to the field, deep plowing to soil rot as base fertilizer.

Return straw to the field can increase the organic matter content of the soil, increase soil nutrients, and enhance soil carbon sequestration capacity. In order to speed up the process of straw return to the field, I suggest one hand, we should actively promote the use of multi-functional combine harvester, on the other hand to transform existing harvesters, the crushed straw or straw bale accessories can be installed on the harvester complete crop harvest complete straw chopping or baling straw field directly, because it promotes recycling.

2) Adhere to the implementation of "One pool three changes"

One pool three changes, which is to build biogas digesters, change water, lavatories, cooking stoves. In recent years, with the continuous improvement of the quality of the lives of farmers, biogas and other new energy sources increasingly favored by people of all ages, Jilin Rural aiming biogas big fuss guide farmers to put aside the traditional bad habits, promote scientific and civilized way of life, and vigorously promote the rural household biogas the construction of One pool three changes project, which is a road to a "stool becomes biogas - methane gas for cooking - the biogas residue becomes organic fertilizer" resources can recycling. The approach of biogas utilization including "pig - Marsh - Tin "and" pig - Marsh - fruit".

3) Use relevant technology to conduct straw to feed

Till 2011, the straw feed processing enterprises in Jilin Province has developed to 130, using straw to feed livestock farms is 2900 , large-scale breeders is 18,000 , the annual production of feed processing straw is 23.425 million tons, 
straw feed utilization rate reached $40 \%$. After years of development, the province straw bluish yellow silo reached 69000 cellar capacity of 8.16 million cubic meters, a straw fodder processing machinery reached 78,000 units. Per ton of straw feed nutritional value equivalent to 270 kilograms of grain feed, it can be used to develop aquaculture, animal husbandry. Saving food and feed resources meanwhile change waste into treasure.

4) Liquefied straw for use of resources

One is the straw using pyrolysis to produce bio-oil, used as fuel for boiler thermal equipment another is straw bioengineering fermentation liquefied to produce fuel ethanol as a clean energy source for the production of life.

Jilin Province in the "12th Five-Year Plan put forward will vigorously promote the non-food raw material substitution, focuses on the development of straw sugar, straw chemical alcohol, straw butanol, and other non-food bio-chemical technology to speed up the pilot and industrialization to achieve non-food from small to large.

\subsection{Base on ecological agriculture, promote clean production}

In recent years, the same time as Jilin Province rural biogas construction number increase rapidly, livestock pens, kitchen, toilet, "three changes" matching rate is not high, the comprehensive utilization of biogas and biogas residue did not play the greatest economic and social benefits. Straw comprehensive utilization rate of the province is lower than $5 \%$ through methane fermentation of animal manure utilization.

Combined impact factors of low-carbon economy in agriculture, we know that to achieve low-carbon agriculture must be rational in organization of production, circulation, marketing all aspects.

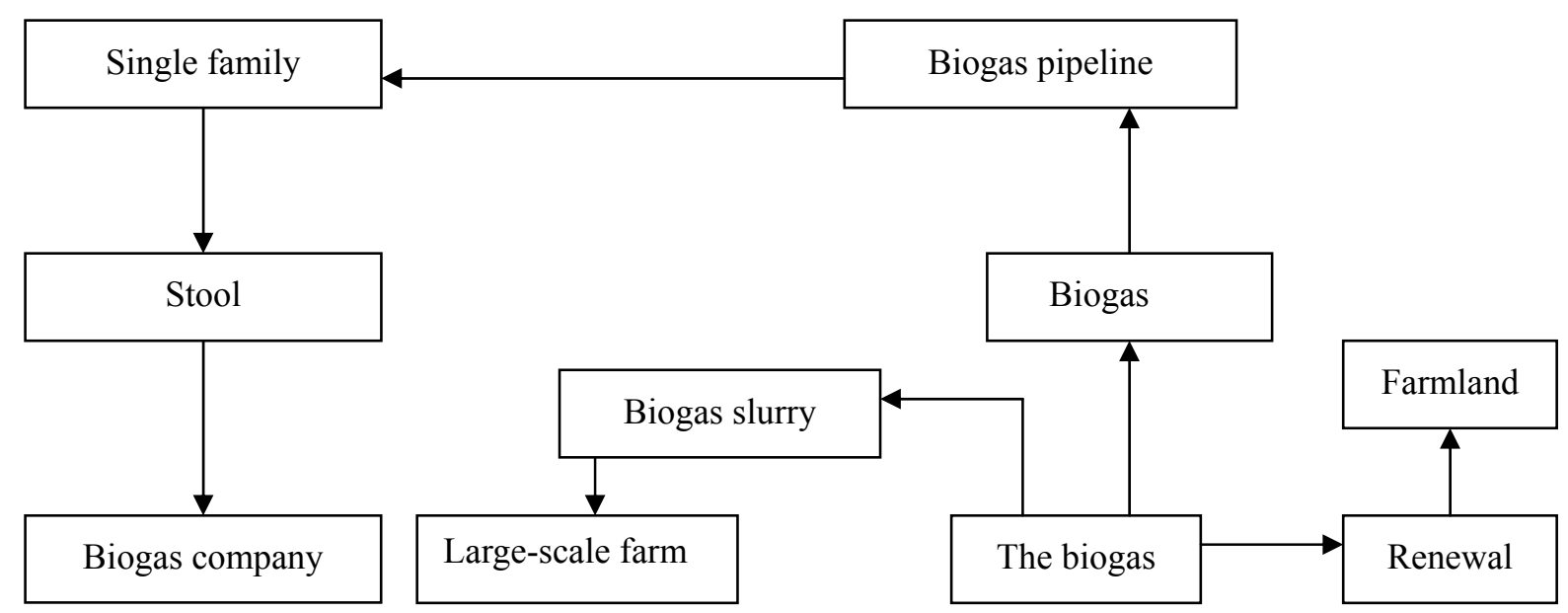

Figure 1. New rural biogas utilization

In this form as figure 1, we will give animal dung disposal to certain size farms and biogas manufacturing company. At the same time, recycle biogas, biogas residue in accordance with the "Pig - Marsh - Field" way. However, the output of biogas is not simply as a gift or welfare, but like liquefied natural gas as a commodity to be sold to farmers, individual farms and biogas manufacturing company can derive some economic benefits.

\section{Summary}

Low-carbon agricultural combines cleaner production and utilization of waste; clean production is the basic form of low-carbon agriculture. Therefore Jilin Province need to strengthen the application of mild environment of new fertilizers and new controlled release fertilizer, the new method of promoting formula fertilization, soil testing, fertilizer, to promote precision fertilizer and other new technologies, trace elements and organic fertilizer blend, combined other methods to increase fertilizer use efficiency and reduce environmental pollution. The perfect "pig Marsh - rice, pig - Marsh - vegetables, pigs - Marsh - Fruit "mode, the farming industry as a leader, biogas construction as the center drive of grain, vegetables, fruit industry, fisheries and other industries extensive comprehensive utilization of agricultural biotechnology, human and animal feces into the pool produce biogas as fuel and lighting, the use of biogas residue and slurry kinds of fruit, fish, pigs, vegetables, multi-level use and development of natural resources, improve economic efficiency and improve the ecological environment. 


\section{References}

H Yan, Wei O L \& Hao G. (2002). DEA models for resource reallocation and production input/ output estimation. European Journal of Operational Research, 136: 19 31.

Kaoru Tone, Miki Tsutsui. (2009). Network DEA: A slacks-based measure approach. European Journal of Operational Research. 197: 243 252.

Kaoru Tone. (2001). A slacks-based measure of efficiency in data envelopment analysis. European Journal of Operational Research, 130: 498 509.

Wei Q L Zhang J \& Zhang X. (2000). An inverse DEA model for input/output estimate. European Journal of Operational Research, 121: 151 163. 